\title{
Surgical management of a giant left main coronary artery aneurysm
}

\author{
Bruno B. Pinheiro, MD, ${ }^{a}$ Walter V. Fagundes, $M D,{ }^{a}$ Carlos A. Gusmão, MD, ${ }^{b}$ \\ Antônio M. C. Lima, MD, ${ }^{\text {b }}$ Lola H. Santos, MD, ${ }^{\text {b }}$ and Gustavo B. Vieira, MD, ${ }^{\text {b }}$ \\ Goiânia, Brazil
}

oronary artery aneurysms are noted in $0.15 \%$ to $4.9 \%$ of patients undergoing coronary angiography. They rarely involve the left main coronary artery (LMCA). In a series of 22,000 coronary angiograms, LMCA aneurysms were found in only 22 patients (an occurrence rate of $0.1 \%){ }^{1}$ According to Lenihan and coworkers, ${ }^{2}$ coronary artery aneurysms in patients younger than 33 years of age are congenital, and they have otherwise normal coronary arteries. In most patients older than 33 years and in all patients older than 56 years, coronary artery aneurysms are caused by atherosclerosis. ${ }^{2}$ The main complication is myocardial ischemia or infarction, but aneurysm rupture can rarely occur. Because of the rarity of LMCA aneurysms, it is difficult to standardize treatment. Various surgical strategies have been adopted, such as reconstruction, resection, or isolation with concomitant coronary bypass. ${ }^{3}$

We present a case of successful isolation of a giant LMCA aneurysm with simultaneous coronary artery bypass grafting.

\section{Clinical Summary}

A 27-year-old man with a history of angina pectoris for 4 months was admitted to the hospital because of progressive precordial pain radiating to the back triggered by physical activity. He had a severe blunt chest injury (car accident) with loss of consciousness 8 years previously.

Results of physical examination were within normal limits. The electrocardiogram showed a normal sinus rhythm. The chest radiograph and transthoracic echocardiogram revealed a huge mass adjacent to the pulmonary trunk and left atrial appendage extrinsically compressing the left atrium. The left ventricular ejection fraction was normal (0.70).

Spiral computed tomography and coronary angiography demonstrated a giant LMCA aneurysm (56 $\mathrm{mm}$ in diameter) without atherosclerotic coronary disease (Figure 1). There was no evidence suggestive of thrombus or dissection.

\footnotetext{
From the Department of Cardiac Surgery, ${ }^{a}$ Hospital Santa GenovevaClinicord, Av. Concordia 26, zip 74670-430, Goiânia, Brazil, and the Department of Cardiology, ${ }^{\mathrm{b}}$ Hospital Geral de Goiânia, Av. Anhanguera 6479, zip 74110-010, Goiânia, Brazil.

Received for publication Feb 20, 2004; revisions requested March 11, 2004; accepted for publication March 15, 2004.

Address for reprints: Bruno B. Pinheiro, MD, Hospital Santa GenovevaClinicord, Av. Concordia 26, zip 74670-430, Goiânia, Brazil (E-mail: bbpmt@cultura.com.br).

J Thorac Cardiovasc Surg 2004;128:751-2

$0022-5223 / \$ 30.00$

Copyright $\odot 2004$ by The American Association for Thoracic Surgery

doi:10.1016/j.jtcvs.2004.03.027
}

The patient was operated on with the aid of cardiopulmonary bypass and antegrade cold blood cardioplegia. The pulmonary trunk was mobilized, and the LMCA aneu-

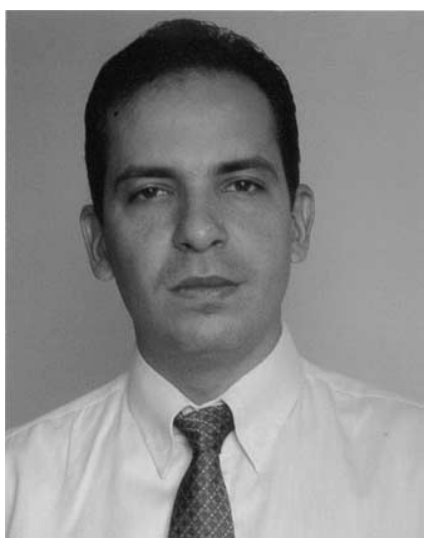

Dr Pinheiro rysm could be exposed and opened (Figure 2). The orifices of the LMCA, the left anterior descending artery, and the circumflex artery were oversewn. The left internal thoracic artery was used to bypass the left anterior descending artery, and the right internal thoracic artery was used to bypass the diagonal branch. A saphenous vein graft was placed to a marginal branch of the circumflex artery. The aortic crossclamp time was 70 minutes, and the cardiopulmonary bypass time was 95 minutes.

The histopathologic study revealed an intimal layer with variable fibrosis and localized tears, medial layer dissection, and fresh intramural hematoma. Medial degeneration, cystic medial necrosis, inflammatory infiltrates, and atherosclerotic plaques were not observed microscopically on the surgical specimen. The patient has been asymptomatic for 5 months after the operation.

\section{Discussion}

The most common cause of aneurysm of the coronary artery is atherosclerosis. The next is idiopathic, often presumed to be congenital. Other causative factors include Takayasu arteritis, Kawasaki disease, Marfan syndrome, systemic lupus erythematosus, Ehlers-Danlos syndrome, polyarteritis nodosa, bacterial infection, syphilis, septic embolism, and trauma. No familial cases of coronary aneurysm have been reported. ${ }^{2,4}$

In our patient the LMCA aneurysm could be classified as congenital. Nevertheless, we cannot exclude the possibility that the chest trauma played a central role in the pathogenesis of his aneurysm.

Patients with aneurysms of the coronary artery diagnosed before death are initially seen most often with angina or myocardial infarction. Often, no physical findings related to aneurysm are present, although both systolic and diastolic murmurs attributed to the aneurysm have been reported. ${ }^{4}$ Rupture of the aneurysm with sudden death is unusual. ${ }^{5}$

In a few patients chest radiography shows a bulge on the cardiac silhouette or calcium in the aneurysm. Transthoracic echocardiography and computed tomography are potentially noninvasive methods of diagnosis, but their value is not yet established. Definitive diagnosis is obtained with coronary angiography. ${ }^{1,4}$

Because of the rarity of LMCA aneurysms, it is difficult to standardize treatment. The conservative treatment consists of attempts to prevent thromboembolic complications with anticoagulants and antiplatelet drugs, but the surgical treatment is most 

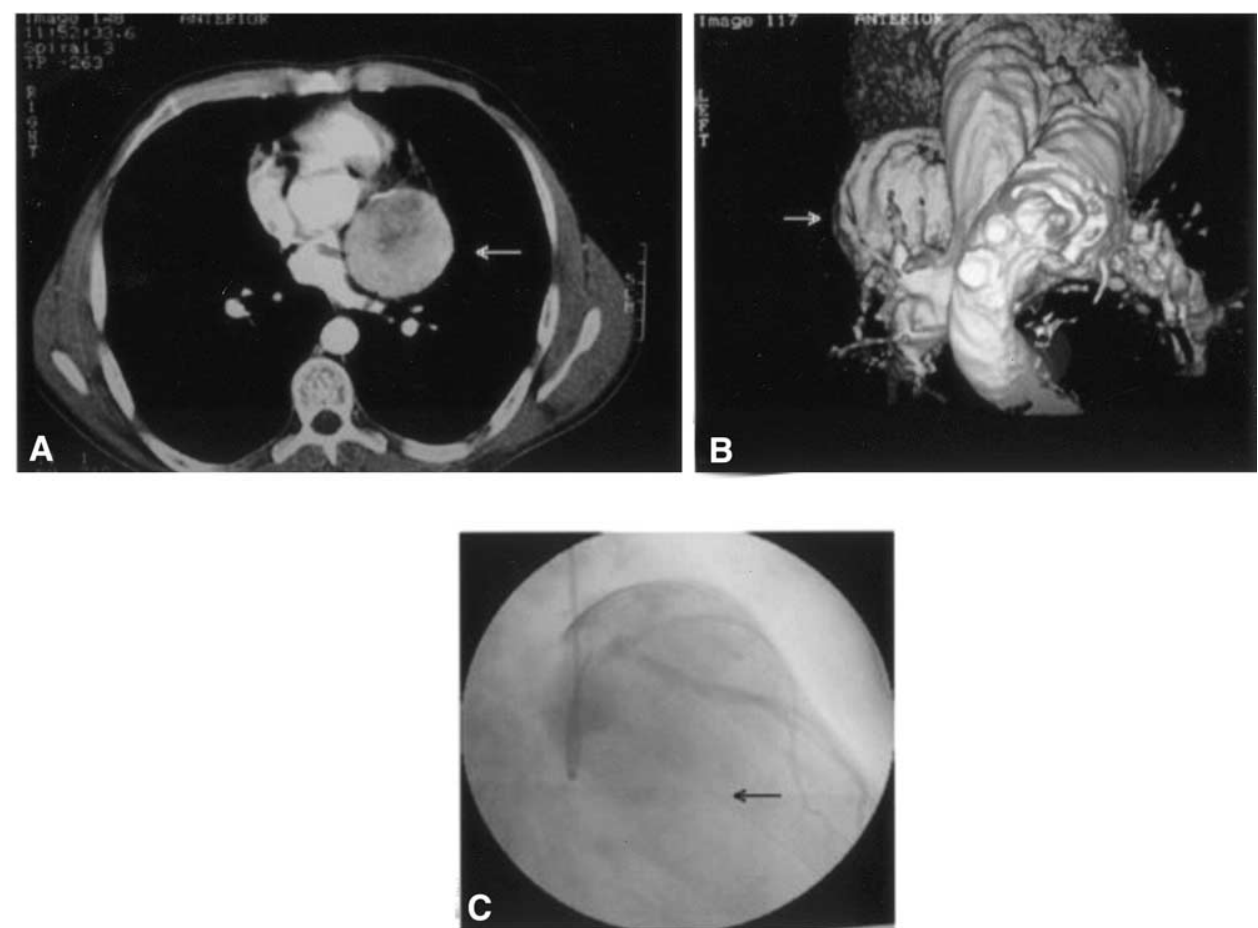

Figure 1. A and B, Spiral computed tomographic scan showing a huge mass (56 $\mathrm{mm}$ in diameter) adjacent to the pulmonary trunk and ascending aorta (white arrow). C, Left coronary angiography.
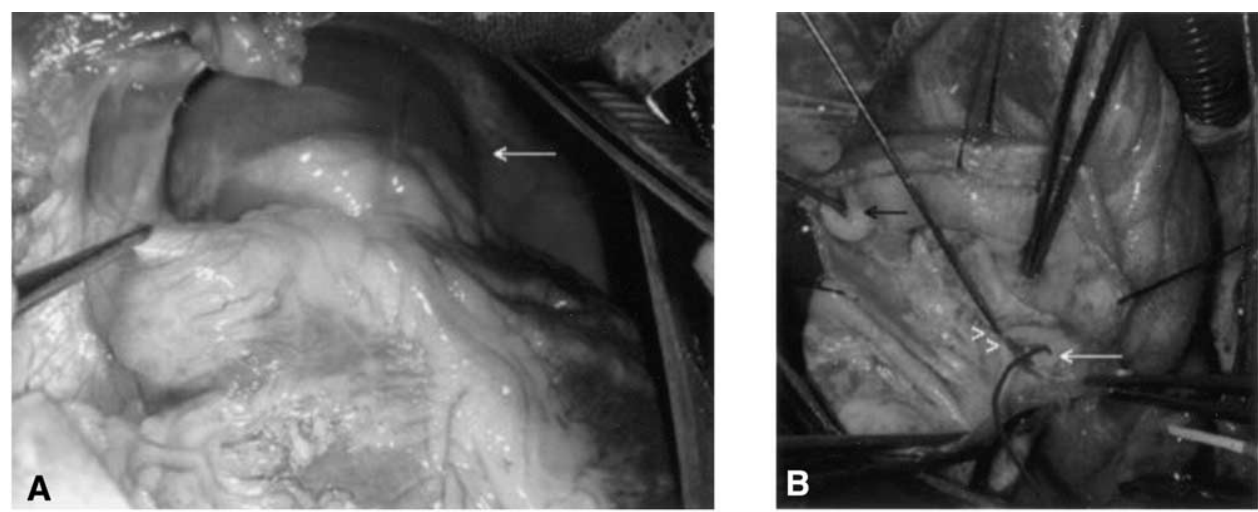

Figure 2. A, Giant LMCA aneurysm (white arrow). B, LMCA aneurysm opened showing the orifices of the left main artery (arrowheads), anterior descending artery (white arrow), and circumflex artery (black arrow).

widely used to avoid complications (extension, thrombosis, rupture, and coronary embolization). Various surgical strategies have been adopted, such as reconstruction, resection, or isolation with concomitant coronary bypass. ${ }^{3-5}$

\section{References}

1. Topaz O, DiSciascio G, Cowley MJ, Goudreau E, Soffer A, Nath A, et al. Angiographic features of the left main coronary artery aneurysms. Am J Cardiol. 1991;67:1139-42.
2. Lenihan DJ, Zeman HS, Collins GJ. Left main coronary artery aneurysm in association with severe atherosclerosis: a case report and review of the literature. Catheter Cardiovasc Diagn. 1991;23:28-31.

3. Lepojärvi M, Salmela E, Huikuri H, Kärkölä P. Repair of an aneurysm of the left main coronary artery. Ann Thorac Surg. 1996;61:1247-9.

4. Moses HW, Huddle RA Jr, Nanda NC, Stewart S, Schreiner BF. Surgical management of an aneurysm of the left main coronary artery. Ann Thorac Surg. 1979;27:569-73.

5. Türkay C, Gölbasi I, Sahin N, Kabukcu M, Bayezid Ö. Surgical management of an atherosclerotic aneurysm of the left main coronary artery. J Thorac Cardiovasc Surg. 2001;122:626-7. 